\title{
$\left[{ }^{18} \mathrm{~F}\right]$ fluorodeoxyglucose uptake patterns in lung before radiotherapy identify areas more susceptible to radiation- induced lung toxicity in non-small-cell lung cancer patients
}

Citation for published version (APA):

Petit, S. F., van Elmpt, W. J. C., Oberije, C. J. G., Vegt, E., Dingemans, A-M. C., Lambin, P., Dekker, A. L. A. J., \& De Ruysscher, D. (2011). [ $\left.{ }^{18} \mathrm{~F}\right]$ fluorodeoxyglucose uptake patterns in lung before radiotherapy identify areas more susceptible to radiation-induced lung toxicity in non-small-cell lung cancer patients. International Journal of Radiation Oncology Biology Physics, 81(3), 698-705.

https://doi.org/10.1016/j.jijrobp.2010.06.016

Document status and date:

Published: 01/11/2011

DOI:

10.1016/j.jijrobp.2010.06.016

Document Version:

Publisher's PDF, also known as Version of record

Document license:

Taverne

Please check the document version of this publication:

- A submitted manuscript is the version of the article upon submission and before peer-review. There can be important differences between the submitted version and the official published version of record.

People interested in the research are advised to contact the author for the final version of the publication, or visit the DOI to the publisher's website.

- The final author version and the galley proof are versions of the publication after peer review.

- The final published version features the final layout of the paper including the volume, issue and page numbers.

Link to publication

\footnotetext{
General rights rights.

- You may freely distribute the URL identifying the publication in the public portal. please follow below link for the End User Agreement:

www.umlib.nl/taverne-license

Take down policy

If you believe that this document breaches copyright please contact us at:

repository@maastrichtuniversity.nl

providing details and we will investigate your claim.
}

Copyright and moral rights for the publications made accessible in the public portal are retained by the authors and/or other copyright owners and it is a condition of accessing publications that users recognise and abide by the legal requirements associated with these

- Users may download and print one copy of any publication from the public portal for the purpose of private study or research.

- You may not further distribute the material or use it for any profit-making activity or commercial gain

If the publication is distributed under the terms of Article $25 \mathrm{fa}$ of the Dutch Copyright Act, indicated by the "Taverne" license above, 


\title{
$\left[{ }^{18}\right.$ F]FLUORODEOXYGLUCOSE UPTAKE PATTERNS IN LUNG BEFORE RADIOTHERAPY IDENTIFY AREAS MORE SUSCEPTIBLE TO RADIATION-INDUCED LUNG TOXICITY IN NON-SMALL-CELL LUNG CANCER PATIENTS
}

\author{
Steven F. Petit, M.Sc., ${ }^{*}$ Wouter J. C. van Elmpt, Ph.D., ${ }^{*}$ Cary J. G. Oberije, M.Sc., ${ }^{*}$ \\ Erik Vegt, M.D. ${ }^{\dagger}$ Anne-Marie C. Dingemans, Ph.D., ${ }^{\ddagger}$ Philippe Lambin, M.D., Ph.D., ${ }^{*}$ \\ André L. A. J. Dekker, Ph.D., * and Dirk De Ruysscher, M.D., Ph.D.* \\ Departments of * Radiation Oncology (MAASTRO), ${ }^{\dagger}$ Nuclear Medicine, and ${ }^{\ddagger}$ Pulmonology, GROW-School for Oncology and \\ Developmental Biology, Maastricht University Medical Centre, Maastricht, The Netherlands
}

\begin{abstract}
Purpose: Our hypothesis was that pretreatment inflammation in the lung makes pulmonary tissue more susceptible to radiation damage. The relationship between pretreatment $\left[{ }^{18} \mathrm{~F}\right]$ fluorodeoxyglucose $\left(\left[{ }^{18} \mathrm{~F}\right] \mathrm{FDG}\right)$ uptake in the lungs (as a surrogate for inflammation) and the delivered radiation dose and radiation-induced lung toxicity (RILT) was investigated.

Methods and Materials: We retrospectively studied a prospectively obtained cohort of 101 non-small-cell lung cancer patients treated with (chemo)radiation therapy (RT). $\left[{ }^{18}\right.$ F]FDG-positron emission tomography-computed tomography (PET-CT) scans used for treatment planning were studied. Different parameters were used to describe $\left[{ }^{18}\right.$ F]FDG uptake patterns in the lungs, excluding clinical target volumes, and the interaction with radiation dose. An increase in the dyspnea grade of 1 (Common Terminology Criteria for Adverse Events version 3.0) or more points compared to the pre-RT score was used as an endpoint for analysis of RILT. The effect of $\left[{ }^{18}\right.$ F]FDG and CT-based variables, dose, and other patient or treatment characteristics that effected RILT was studied using logistic regression.

Results: Increased lung density and pretreatment $\left[{ }^{18}\right.$ F $]$ FDG uptake were related to RILT after RT with univariable logistic regression. The 95th percentile of the $\left[{ }^{18}\right.$ F]FDG uptake in the lungs remained significant in multivariable logistic regression $(p=0.016 ;$ odds ratio $[O R]=4.3)$, together with age $(p=0.029 ; O R=1.06)$, and a pre-RT dyspnea score of $\geq 1(p=0.005 ; O R=0.20)$. Significant interaction effects were demonstrated among the 80th, 90th, and 95th percentiles and the relative lung volume receiving more than 2 and $5 \mathrm{~Gy}$.

Conclusions: The risk of RILT increased with the 95th percentile of the $\left[{ }^{18}\right.$ F]FDG uptake in the lungs, excluding clinical tumor volume $(\mathrm{OR}=4.3)$. The effect became more pronounced as the fraction of the $5 \%, 10 \%$, and $20 \%$ highest standardized uptake value voxels that received more than $2 \mathrm{~Gy}$ to $5 \mathrm{~Gy}$ increased. Therefore, the risk of RILT may be decreased by applying sophisticated radiotherapy techniques to avoid areas in the lung with high $\left[{ }^{18}\right.$ F]FDG uptake. (c) 2011 Elsevier Inc.
\end{abstract}

Radiation-induced lung toxicity (RILT), Pneumonitis, Fluorodeoxyglucose (FDG), Positron emission tomography (PET), Dyspnea, Lung.

\section{INTRODUCTION}

Approximately $10 \%$ to $20 \%$ of all lung cancer patients treated with radiotherapy (RT) suffer from radiation-induced lung toxicity (RILT). RILT is an important and dose-limiting complication related to the volume of the lungs that is irradiated and the radiation dose $(1,2)$. Several treatment-related param- eters and patient characteristics have been described that increase the risk of RILT. The parameters most consistently reported are the volume of the lung receiving more than 5 Gy or $20 \mathrm{~Gy}\left(\mathrm{~V}_{5}\right.$ or $\left.\mathrm{V}_{20}\right)$ and the mean lung dose (MLD) (3-7). Age, forced expiratory volume in 1 second $\left(\mathrm{FEV}_{1}\right)$, World Health Organization (WHO) performance status, tumor location, and different blood biomarkers may also
Reprint requests to: Steven Petit, M.Sc., Department of Radiation Oncology (MAASTRO clinic), GROW - School for Oncology and Developmental Biology, Maastricht University Medical Centre, Dr. Tanslaan 12, NL-6229 ET Maastricht, The Netherlands. Tel: (+31) 884455 666; Fax: (+31) 884455 667; E-mail: steven.petit@ maastro.nl

André L. A. J. Dekker and Dirk De Ruysscher contributed equally to this work.

This work was supported by the ALLEGRO project (early and late health risks to normal/healthy tissues from the use of existing and emerging techniques for radiation therapy, FP7 framework, Grant agreement no. 231965).

Conflict of interest: none.

Acknowledgment - This study was performed within the framework of the Center for Translational Molecular Medicine (www.ctmm.nl), project AIRFORCE no. 03O-103.

Received Dec 31, 2009, and in revised form April 8, 2010. Accepted for publication June 17, 2010. 
have an influence on RILT (3,8-10). Although the MLD can be safely used for individualized dose prescription (11), the present parameters do not allow identification of individuals or strategies that are suitable for radiation dose escalation.

As RILT has an important inflammatory component (12), we hypothesized that pretreatment inflammation in the lung would make pulmonary tissue more susceptible to radiation damage. An increased uptake of $\left[{ }^{18} \mathrm{~F}\right]$ fluorodeoxyglucose $\left(\left[{ }^{18} \mathrm{~F}\right] \mathrm{FDG}\right)$ has already been associated with a number of inflammatory, nonmalignant disorders (13-18). A high and diffuse $\left[{ }^{18} \mathrm{~F}\right] \mathrm{FDG}$ uptake after the end of RT has been reported for patients with radiation pneumonitis $(19,20)$. It has been shown that $\left[{ }^{18} \mathrm{~F}\right] \mathrm{FDG}$ uptake in different parts of the lung after the end of RT depends on the administered radiation dose $(21,22)$. Patients with a high metabolic response to radiation were more likely to develop radiation pneumonitis $(23,22)$. Also, an increase in $\left[{ }^{18} \mathrm{~F}\right] \mathrm{FDG}$ uptake during the first 2 weeks of RT has been described as prognostic for RILT (24). Inflammation in the lungs before treatment could make inflamed parts of the lungs more susceptible to RT. Therefore, the question arises whether high $\left[{ }^{18} \mathrm{~F}\right] \mathrm{FDG}$ uptake in the lungs before RT is related to RILT after RT. If this were the case, a direct therapeutic strategy would emerge, avoiding irradiation of the high- $\left[{ }^{18} \mathrm{~F}\right] \mathrm{FDG}-$ uptake regions in the lungs.

The present study presents an explorative analysis in a group of 101 non-small-cell lung cancer (NSCLC) patients who were treated with (chemo)radiation therapy. The aim was to characterize the relationship between pretreatment $\left[{ }^{18}\right.$ F]FDG uptake in the lungs and the development of RILT and to determine the effect of radiation dose on this relationship. Inflammation may also be detected on computed tomography (CT), where inflamed lung regions can show as an increased density (infiltration).To determine the added value of $\left[{ }^{18} \mathrm{~F}\right]$ FDG-positron emission tomography (PET) compared to CT, Hounsfield unit (HU) distributions in the lungs were analyzed as well.

\section{METHODS AND MATERIALS}

\section{Patient population and treatment}

A retrospective analysis was performed of a prospectively obtained cohort of 101 NSCLC patients treated between May 2006 and September 2009 at our institution. Before the start of RT, all patients had a respiratory-gated four-dimensional CT (4D-CT) scan directly followed by an $\left[{ }^{18} \mathrm{~F}\right]$ FDG-PET scan with the same clinical PET/CT scanner (TruePoint Biograph 40; Siemens, Erlangen, Germany). PET scans were corrected for scatter, decay, and attenuation by using the mid-ventilation CT phase. Standardized uptake values (SUVs) were calculated according to the following formula: SUV = [decay corrected activity $(\mathrm{Bq}) /$ tissue volume $(\mathrm{ml})] /$ [injected activity (Bq)/body weight (g)]).

After 4D-CT and PET scans were performed, a low-dose CT scan with intravenous contrast medium was obtained from the patients. The mid-ventilation phase of the 4D-CT was used for treatment planning.

The normal tissues and the gross tumor volume (GTV) were delineated on the CT scans by a radiation oncologist. The clinical and planning target volumes (CTV and PTV) were generated by expand- ing the GTV with a margin of 5 and $15 \mathrm{~mm}$, respectively. Only lymph nodes that were positive on $\left[{ }^{18} \mathrm{~F}\right]$ FDG-PET or pathology were treated. These areas were combined in a separate GTV that was expanded with a margin of $5 \mathrm{~mm}$ to the CTV and with another $5 \mathrm{~mm}$ to the PTV.

Patients were treated with curative or palliative intent with RT alone; with concurrent chemoradiation consisting of cisplatin and vinorelbine or cisplatin and etoposide; or with sequential chemoradiation with carboplatin and gemcitabine. All patients were treated with 3D conformal RT. Radiotherapy was delivered once or twice daily in a fraction of $1.5,1.8$, or $2 \mathrm{~Gy}$. The total dose varied between 28.5 and 79.2 Gy $(25,26)$. The prescribed doses to the PTV of the primary tumor and to the lymph nodes were equal. Treatment planning was performed with a clinical treatment planning system (XiO version 4.3.4; CMS, St. Louis, MO) using the superposition algorithm with inhomogeneity corrections.

\section{Image analysis}

Image analysis was performed with Matlab (version 2008b; MathWorks Inc., Natick, MA). Dose distributions were interpolated to the coordinate system of the PET scans, using a 3D linear interpolation algorithm. The volume of interest (VOI) consisted of the lungs, excluding the CTV(s). In some cases, breathing or cardiac motion caused spillover of the PET signal of the heart in the VOI. These regions were manually delineated and excluded from the VOI. Spillover out of the tumor can also occur, but this is usually restricted to the CTV.

The SUV of all voxels in the VOI were binned in histograms, and the mean SUV ( $\left(\mathrm{SUV}_{\text {mean }}\right)$, the standard deviation (SD) of the SUV $\left(\mathrm{SUV}_{\mathrm{SD}}\right)$, and the maximum SUV $\left(\mathrm{SUV}_{\max }\right)$ were calculated. In addition, the 80th, 90th, and 95th percentiles of the SUV were calculated $\left(\mathrm{SUV}_{80}, \mathrm{SUV}_{90}, \mathrm{SUV}_{95}\right.$, respectively). For example, $\mathrm{SUV}_{80}$ refers to the SUV value below which $80 \%$ of the voxels fall. These parameters are referred to as the $\left[{ }^{18} \mathrm{~F}\right] \mathrm{FDG}$-based variables.

To determine if a PET scan had added value for the prediction of RILT, the parameters mentioned above were also calculated for $\mathrm{HU}$ of the CT scan: the $\mathrm{HU}_{\text {mean }}, \mathrm{HU}_{\mathrm{SD}}, \mathrm{HU}_{\max }, \mathrm{HU}_{80}, \mathrm{HU}_{90}$, and $\mathrm{HU}_{95}$. These parameters are referred to as the HU-based variables.

\section{Influence of dose on high- $\left[{ }^{18} \mathrm{~F}\right] \mathrm{FDG}$-uptake regions}

If high $\left[{ }^{18} \mathrm{~F}\right] \mathrm{FDG}$ uptake in the lungs is related to an increased risk of RILT, the dose to these regions might be of importance. The high[18F]FDG-uptake voxels were defined as all voxels with a SUV higher than $\mathrm{SUV}_{80}, \mathrm{SUV}_{90}$, or $\mathrm{SUV}_{95}$. This corresponded to the $20 \%, 10 \%$, and $5 \%$ highest $\left[{ }^{18} \mathrm{~F}\right] \mathrm{FDG}$ uptake voxels, respectively. The effect of dose on these voxels was analyzed by calculating the portion of these voxels that received more than $2,5,10$, and $20 \mathrm{~Gy}$. This is equivalent to the overlap between, the overlap between the highest $\left[{ }^{18} \mathrm{~F}\right] \mathrm{FDG}$ voxels and the lung volume receiving more than $2,5,10$, and $20 \mathrm{~Gy}\left(\mathrm{~V}_{2}, \mathrm{~V}_{5}, \mathrm{~V}_{10}\right.$, and $\left.\mathrm{V}_{20}\right)$, respectively. This overlap was defined as Overlapsuv $x, D=[$ Volume with SUV $>$ $\mathrm{SUV}_{x}$ and Dose $\left.>D\right] /\left[\right.$ Volume with SUV $\left.>\mathrm{SUV}_{x}\right]$ and was calculated for the SUV volumes with $\mathrm{SUV}>\mathrm{SUV}_{80}, \mathrm{SUV}>\mathrm{SUV}_{90}$, and $\mathrm{SUV}>\mathrm{SUV}_{95}$ and dose volumes receiving more than $2,5,10$, and $20 \mathrm{~Gy}\left(\mathrm{~V}_{2}, \mathrm{~V}_{5}, \mathrm{~V}_{10}, \mathrm{~V}_{20}\right)$.

\section{Toxicity scoring}

Toxicity was scored by the radiation oncologist according to Common Terminology Criteria for Adverse Events version 3.0 before, during, and after treatment. The pre-RT (baseline) dyspnea score was compared to the post-RT score, defined as the maximum dyspnea score during or up to 3 months after RT. An increase in 
Table 1. Patient characteristics

\begin{tabular}{|c|c|}
\hline Characteristic & Value \\
\hline \multicolumn{2}{|l|}{ Gender } \\
\hline Male & $68(67 \%)$ \\
\hline Female & $33(33 \%)$ \\
\hline \multicolumn{2}{|l|}{ Age (years) } \\
\hline Median & 64 \\
\hline Range & $43-85$ \\
\hline \multicolumn{2}{|l|}{ Disease stage } \\
\hline I & $7(8 \%)$ \\
\hline II & $5(5 \%)$ \\
\hline III & $81(80 \%)$ \\
\hline IV & $7(7 \%)$ \\
\hline \multicolumn{2}{|l|}{ WHO } \\
\hline 0 & $43(43 \%)$ \\
\hline 1 & $45(45 \%)$ \\
\hline 2 & $9(9 \%)$ \\
\hline 3 & $3(3 \%)$ \\
\hline Missing & $1(1 \%)$ \\
\hline \multicolumn{2}{|c|}{ COPD grade (GOLD classification) } \\
\hline $0-\mathrm{I}$ & $46(46 \%)$ \\
\hline II & $48(48 \%)$ \\
\hline III & $7(7 \%)$ \\
\hline IV & $0(0 \%)$ \\
\hline \multicolumn{2}{|l|}{$\mathrm{FEV}_{1}(\%)$} \\
\hline Median & 79 \\
\hline Range & $32-140$ \\
\hline \multicolumn{2}{|l|}{ Smoking } \\
\hline Yes & $36(36 \%)$ \\
\hline No & $54(53 \%)$ \\
\hline Missing & $11(11 \%)$ \\
\hline \multicolumn{2}{|l|}{ Tumor load } \\
\hline Median & 74.4 \\
\hline Range & $3-474$ \\
\hline \multicolumn{2}{|l|}{ Chemotherapy } \\
\hline None & $12(12 \%)$ \\
\hline Induction before RT & $28(27 \%)$ \\
\hline Concurrent with RT & $60(60 \%)$ \\
\hline \multicolumn{2}{|l|}{ Prescription dose (Gy) } \\
\hline Median & 61.2 \\
\hline Range & $28.5-79.2$ \\
\hline \multicolumn{2}{|l|}{ MLD (Gy) } \\
\hline Median & 14.8 \\
\hline Range & $2.4-20.8$ \\
\hline \multicolumn{2}{|l|}{$\mathrm{V}_{20}(\%)$} \\
\hline Median & 26 \\
\hline Range & $3-51$ \\
\hline \multicolumn{2}{|l|}{ Follow up (days) } \\
\hline Median & 354 \\
\hline Range & $39-1,268$ \\
\hline
\end{tabular}

Abbreviations: $\mathrm{WHO}=$ World Health Organization performance status; $\mathrm{FEV}_{1}$ = forced expiratory volume in 1 second; $\mathrm{MLD}=$ mean lung dose; $\mathrm{V}_{20}=$ relative volume of the lung receiving more than 20 Gy; GOLD = global initiative for chronic obstructive lung disease; $\mathrm{RT}=$ radiotherapy.

dyspnea grade of 1 or more points after RT was defined as RILT and as an endpoint for statistical analyses.

\section{Statistical analyses}

Univariable logistic regression was used to investigate the relationship between HU-based and $\left[{ }^{18} \mathrm{~F}\right]$ FDG-based variables and RILT. In addition, a set of non- $\left[{ }^{18} \mathrm{~F}\right] \mathrm{FDG}$-based variables that have been associated previously with RILT were considered. These included age, WHO performance status, $\mathrm{FEV}_{1}$, smoking status at the

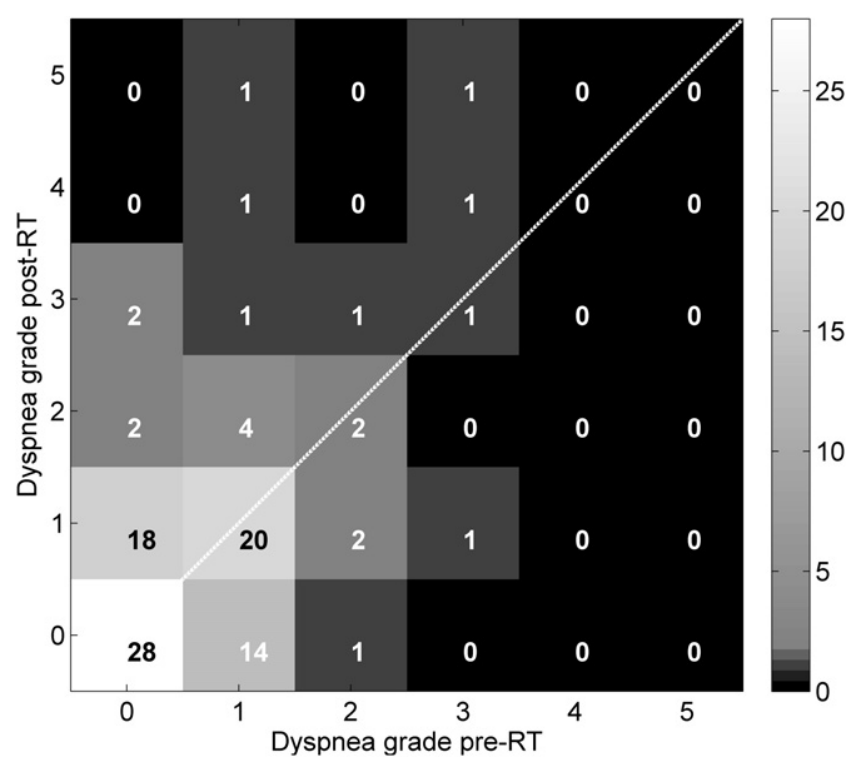

Fig. 1. Overview of the number of patients with the dyspnea scores before the start of RT (horizontal axis) and the maximum scores during or at maximum 3 months after treatment (vertical axis). Patients above, on, or below the diagonal had an increase, remained stable, or had a decrease in dyspnea grade, respectively.

start of treatment (yes/no), the $\mathrm{V}_{20}, \mathrm{~V}_{10}, \mathrm{~V}_{5}$, and $\mathrm{V}_{2}$, and MLD. Two variables were used to model concurrent chemotherapy (yes/no) and sequential chemotherapy (yes/no). Also, the dyspnea baseline score was included, using dummy variables (baseline score $=1$; yes/no) and (baseline score $\geq 2$, yes/no).

For the multivariable logistic regression, a stepwise backward procedure based on the log likelihood ratio was applied. To avoid over-fitting, the full model contained only variables that had $p$ values of $<0.10$ with univariable regression. If HU- or $\left[{ }^{18} \mathrm{~F}\right] \mathrm{FDG}-$ based variables were highly correlated (Spearman's rank correlation coefficient of $>0.8$ ), only the variable with the lowest $p$ value with univariable logistic regression was included.

The SUV values of the highest percentage of $\left[{ }^{18} \mathrm{~F}\right] \mathrm{FDG}$ voxels can differ considerably among different patients. Therefore, the overlap between the $5 \%$ to $20 \%$ highest voxels and the dose volumes is meaningless without considering the absolute SUV values of the 95th to 80th percentiles $\left(\mathrm{SUV}_{95}, \mathrm{SUV}_{90}\right.$, and $\left.\mathrm{SUV}_{80}\right)$ that are the cut-off points of the $5 \%$ to $20 \%$ highest $\left[{ }^{18} \mathrm{~F}\right] \mathrm{FDG}$ voxels. For that reason, the effect of dose on the highest $\left[{ }^{18} \mathrm{~F}\right] \mathrm{FDG}$ voxels in RILT was studied by testing the significance of the interaction terms, $\mathrm{SUV}_{x} \times$ Overlap $_{\mathrm{SUV} x, D}$. This was done as follows: a logistic regression model containing only $\mathrm{SUV}_{x}$ was compared to a model that contained $\mathrm{SUV}_{x}$ and Overlap $\mathrm{SUV}_{x, D}$. Next, the interaction term $\mathrm{SUV}_{x} \times$ Overlap $_{\mathrm{SUV} x, D}$ was added. If the interaction term was significant, we concluded that the dose to the $x \%$ highest $\left[{ }^{18} \mathrm{~F}\right] \mathrm{FDG}$ voxels influenced the effect of $\left[{ }^{18}\right.$ F]FDG uptake on RILT. Because of the limited amount of events in this study, the interaction terms of dose and SUV were not tested together with the non- $\left[{ }^{18}\right.$ F]FDGbased variables.

Variables with missing values were imputed using single imputation, based on the predictive mean matching method. Observations were considered outliers if Cook's distance was larger than 1. In these cases, the results are presented both with and without the outliers. Linearity of the HU- and $\left[{ }^{18}\right.$ F]FDG-based variables with the log odds was verified by categorizing the variables in three equal bins of around 34 patients each. The categorized variable was added 
to the univariable logistic regression model with the original continuous variable as the only predictor. If the addition of the categorized variable was significant, it was concluded that the variable was nonlinear with the log odds and that the categorized variable was used throughout the study instead. All statistical tests were performed with SPSS software (version 15.0; Chicago, IL) using the log likelihood ratio test. A $p$ value of $<0.05$ was considered statistically significant.

\section{RESULTS}

An overview of the patient and treatment characteristics is presented in Table 1 . The baseline and maximum dyspnea scores after RT are shown in Fig. 1. On average, 32\% of the patients developed RILT, i.e., had an increase in dyspnea score. Eighteen patients (17\%) had a post-RT dyspnea score of $\geq 2$; 41 patients $(41 \%)$ had post-RT scores of 1 ; and 43 patients $(43 \%)$ did not have dyspnea post-RT. Forty-eight patients had moderate chronic obstructive pulmonary disease (grade 2) before the start of RT, and 7 patients had severe chronic obstructive pulmonary disease (grade 3 ) according to the GOLD classification (27). Two of the patients with RILT died (grade 5) from respiratory failure, 39 and 40 days after the start of RT.
The results of the univariable logistic regressions are summarized in Table 2. Age $(p=0.025)$ and the dyspnea scored before the start of RT $(p=0.020)$ were significant predictors of RILT. Also, an increased lung density was associated with an increased risk of RILT, indicated by four HU-based variables that were significant predictors, namely, the standard deviation $(p=0.005)$, and the 80th $(p=0.043)$, 90th $(p=$ $0.019)$, and 95th $(p=0.022)$ percentiles of the Hounsfield units in the lung.

Also the standard deviation $(p=0.007)$ and the 90th $(p=$ $0.015)$ and 95 th $(p=0.011)$ percentiles of $\left[{ }^{18} \mathrm{~F}\right] \mathrm{FDG}$ uptake in the lungs were significant predictors, with univariable logistic regression. No linearity problems were encountered in the analysis. The Spearman correlation coefficients between the significant $\mathrm{HU}$ - and $\left[{ }^{18} \mathrm{~F}\right] \mathrm{FDG}$-based variables are shown in Table 3. Although $\operatorname{SUV}_{\mathrm{SD}}$ had the lowest $p$ value of the $\left[{ }^{18} \mathrm{~F}\right] \mathrm{FDG}$-based parameters, it was not used for the multivariable analysis because the estimation of its coefficients were unstable, as indicated by the large confidence interval. Instead, $\mathrm{SUV}_{95}$ was used.

The final multivariable logistic regression model was composed of age, a dyspnea score before RT, and $\mathrm{SUV}_{95}$ (Table 4). A high age and $\mathrm{SUV}_{95}$ value increased the risk

Table 2. Results of univariable logistic regression analyses

\begin{tabular}{|c|c|c|c|c|}
\hline Parameter & Coefficient & SE & Odds ratio $(95 \% \mathrm{CI})$ & $p$ value \\
\hline \multicolumn{5}{|l|}{ Patient characteristics } \\
\hline Gender & -0.31 & 0.47 & $0.73(0.29-1.8)$ & 0.504 \\
\hline Age & 0.049 & 0.023 & $1.6(1.6-1.7)$ & 0.025 \\
\hline $\mathrm{FEV}_{1}$ & -0.0080 & 0.011 & $0.99(0.97-1.01)$ & 0.482 \\
\hline Smoking & -0.44 & 0.44 & $0.64(0.27-1.5)$ & 0.314 \\
\hline WHO performance status 1 & -0.14 & 0.46 & $0.87(0.35-2.1)$ & 0.707 \\
\hline WHO performance status $\geq 2$ & 0.43 & 0.7 & $1.5(0.39-6.1)$ & \\
\hline Tumor dose & -0.026 & 0.024 & $0.97(0.93-1.02)$ & 0.273 \\
\hline $\mathrm{V}_{20}$ & 0.014 & 0.023 & $1.0(0.97-1.06)$ & 0.551 \\
\hline $\mathrm{V}_{10}$ & 0.018 & 0.016 & $1.0(0.99-1.05)$ & 0.252 \\
\hline $\mathrm{V}_{5}$ & 0.018 & 0.014 & $1.0(0.99-1.05)$ & 0.177 \\
\hline $\mathrm{V}_{2}$ & 0.015 & 0.012 & $1.0(0.99-1.04)$ & 0.222 \\
\hline MLD & 0.043 & 0.054 & $1.0(0.94-1.16)$ & 0.42 \\
\hline Dypnea pre-RT $=1$ & -1.3 & 0.50 & $0.26(0.10-0.70)$ & 0.020 \\
\hline Dypnea pre-RT > 1 & -0.61 & 0.75 & $0.54(0.12-2.4)$ & \\
\hline Chemotherapy, sequential & -0.80 & 0.70 & $0.45(0.11-1.8)$ & 0.358 \\
\hline Chemotherapy, concurrent & -0.93 & 0.65 & $0.39(0.11-1.4)$ & \\
\hline \multicolumn{5}{|l|}{ HU-based variables } \\
\hline $\mathrm{HU}_{\text {mean }}$ & 0.0060 & 0.004 & $1.01(1.00-1.01)$ & 0.172 \\
\hline $\mathrm{HU}_{\mathrm{SD}}$ & 0.034 & 0.013 & $1.03(1.01-1.06)$ & 0.005 \\
\hline $\mathrm{HU}_{\max }$ & $-3.410^{-4}$ & $5.210^{-4}$ & $1.00(1.00-1.00)$ & 0.481 \\
\hline $\mathrm{HU}_{80}$ & $5.310^{-3}$ & $2.710^{-3}$ & $1.01(1.00-1.01)$ & 0.043 \\
\hline $\mathrm{HU}_{90}$ & $6.110^{-3}$ & $2.710^{-3}$ & $1.01(1.00-1.01)$ & 0.019 \\
\hline $\mathrm{HU}_{95}$ & $7.710^{-3}$ & $3.610^{-3}$ & $1.01(1.00-1.01)$ & 0.022 \\
\hline \multicolumn{5}{|l|}{ FDG-based variables } \\
\hline $\mathrm{SUV}_{\text {mean }}$ & 2.1 & 1.2 & $7.77(0.78-77)$ & 0.057 \\
\hline $\mathrm{SUV}_{\mathrm{SD}}$ & 5.6 & 2.3 & $2.710^{2}\left(2.9-2.510^{4}\right)$ & 0.007 \\
\hline $\mathrm{SUV}_{\max }$ & 0.13 & 0.12 & $1.1(0.90-1.4)$ & 0.288 \\
\hline $\mathrm{SUV}_{80}$ & 1.8 & 0.93 & $5.8(0.93-36)$ & 0.041 \\
\hline $\mathrm{SUV}_{90}$ & 1.7 & 0.75 & $5.3(1.2-23)$ & 0.015 \\
\hline $\mathrm{SUV}_{95}$ & 1.4 & 0.62 & $4.2(1.3-14)$ & 0.011 \\
\hline
\end{tabular}

Abbreviations: $\mathrm{SE}=$ standard error; $\mathrm{CI}=$ confidence interval; $\mathrm{FEV}_{1}=$ forced expiratory volume in 1 second; WHO = World Health Organization performance status; $\mathrm{V}_{\mathrm{x}}=$ lung volume that received a dose of $>\mathrm{x} ; \mathrm{HU}=$ Hounsfield units; $\mathrm{SUV}=$ standardized uptake values; SD = standard deviation; $\max =$ maximum.

Numerical subscripts denote percentiles, i.e., $\mathrm{SUV}_{80}$ is the 80 th percentile of the SUV in the lungs. 
Table 3. Spearman rank correlation coefficients of the HU- and $\left[{ }^{18} \mathrm{~F}\right] \mathrm{FDG}$-based variables that were significant with univariable logistic regression

\begin{tabular}{lcccccccc}
\hline Variable & $\mathrm{HU}_{\mathrm{SD}}$ & $\mathrm{HU}_{80}$ & $\mathrm{HU}_{90}$ & $\mathrm{HU}_{95}$ & $\mathrm{SUV}_{\mathrm{SD}}$ & $\mathrm{SUV}_{80}$ & $\mathrm{SUV}_{90}$ & $\mathrm{SUV}_{95}$ \\
\hline $\mathrm{HU}_{\mathrm{SD}}$ & 1.00 & 0.47 & 0.62 & 0.72 & 0.28 & 0.19 & 0.21 & 0.22 \\
$\mathrm{HU}_{80}$ & 0.47 & 1.00 & 0.97 & 0.88 & 0.44 & 0.62 & 0.60 & 0.56 \\
$\mathrm{HU}_{90}$ & 0.62 & 0.97 & 1.00 & 0.95 & 0.44 & 0.57 & 0.56 & 0.53 \\
$\mathrm{HU}_{95}$ & 0.72 & 0.88 & 0.95 & 1.00 & 0.34 & 0.46 & 0.45 & 0.42 \\
$\mathrm{SUV}_{\mathrm{SD}}$ & 0.28 & 0.44 & 0.44 & 0.34 & 1.00 & 0.84 & 0.89 & 0.92 \\
$\mathrm{SUV}_{80}$ & 0.19 & 0.62 & 0.57 & 0.46 & 0.84 & 1.00 & 0.99 & 0.97 \\
SUV $_{90}$ & 0.21 & 0.60 & 0.56 & 0.45 & 0.89 & 0.99 & 1.00 & 0.99 \\
SUV $_{95}$ & 0.22 & 0.56 & 0.53 & 0.42 & 0.92 & 0.97 & 0.99 & 1.00 \\
\hline
\end{tabular}

Abbreviations: $\mathrm{HU}=$ Hounsfield unit; SUV = standardized uptake value; SD = standard deviation.

Numerical subscripts indicate percentile values, e.g., $\mathrm{SUV}_{80}$ denotes the 80 th percentile of the SUV in the lungs.

of RILT. Pre-treatment dyspnea had an opposite effect, indicating that patients with dyspnea before RT (score 1 or higher) were less likely to have an increase in dyspnea than patients without baseline dyspnea. The HU-based variables lost their statistical significance in the multivariable analysis.

The mean overlap between the $20 \%$ highest $\left[{ }^{18} \mathrm{~F}\right] \mathrm{FDG}$ uptake voxels and the dose volumes varied from $30 \%\left(\mathrm{~V}_{20}\right)$ to $60 \%\left(\mathrm{~V}_{2}\right)$. For the $10 \%$ and $5 \%$ highest $\left[{ }^{18} \mathrm{~F}\right] \mathrm{FDG}$ uptake voxels, the numbers were comparable and ranged from $31 \%\left(\mathrm{~V}_{20}\right)$ to $60 \%\left(\mathrm{~V}_{2}\right)$ and $32 \%\left(\mathrm{~V}_{20}\right)$ to $59 \%\left(\mathrm{~V}_{2}\right)$. The overlap between any of the iso-dose surfaces and the 5\% to $20 \%$ highest $\left[{ }^{18} \mathrm{~F}\right] \mathrm{FDG}$ uptake voxels was, by itself, not statistically significant. However interaction effects were demonstrated between the SUV percentiles and the overlap of the highest SUV voxels with $V_{2}$ and $V_{5}$ (Table 5). This means that the effect of the SUV distribution in the lungs on RILT depended on the overlap between the highest SUV voxels with the $\mathrm{V}_{2}$ and $\mathrm{V}_{5}$. A large overlap yielded a large risk of RILT. For example, an overlap of $50 \%$ between $\mathrm{V}_{5}$ and the $5 \%$ highest $\left[{ }^{18} \mathrm{~F}\right] \mathrm{FDG}$ uptake voxels resulted in an odds ratio (OR) for $\mathrm{SUV}_{95}$ of 2.80 compared to an OR of 91 for an overlap of $90 \%$.

Figure 2 shows the $\mathrm{SUV}_{95}$ versus the Overlap value between the $\mathrm{V}_{2}$ and the $5 \%$ highest $\left[{ }^{18} \mathrm{~F}\right] \mathrm{FDG}$ uptake voxels Overlap $_{\text {suv95 }}, 2$ Gy. Ten of 13 patients $(77 \%)$ with an $\mathrm{SUV}_{95}$ of $>1.2$ and an Overlap Suv95 $_{2}, 2 \mathrm{~Gy}$, of $>50 \%$ had RILT, compared to 1 of 10 patients (10\%) with an $\mathrm{SUV}_{95}$ of $>1$ and Overlap suv $95,2 \mathrm{~Gy}$, of $<50 \%$. No influence of the $\mathrm{V}_{10}$ and $\mathrm{V}_{20}$ was found.
The location of the 5\% voxels with the highest uptake was studied for the patients with $\mathrm{SUV}_{95}$ of $>1.2$. For only 1 patient, they were limited to one lung only. No relationship was observed with the location of the tumor. For 6 of 11 patients with RILT, the high SUV regions were located mainly in the lower part of the lungs, whereas all patients without RILT $(n=12)$ showed an equal spread in the cranialcaudal direction. For 9 of 12 patients without RILT, the high uptake zones were located mainly near the central sagittal plane. No distinction in the left-right direction was observed for the patients with RILT. Figure 3 shows $\left[{ }^{18}\right.$ F]FDG-PET-CT scans of three patients with high $\left[{ }^{18} \mathrm{~F}\right]$ FDG uptake in the lungs.

\section{DISCUSSION}

We investigated the effect of $\left[{ }^{18} \mathrm{~F}\right] \mathrm{FDG}$ uptake in the lungs on subsequent cases of RILT. Patients with high $\left[{ }^{18} \mathrm{~F}\right] \mathrm{FDG}$ uptake before RT in 5\% to $10 \%$ of the lungs were more likely to develop RILT after RT than patients with a low uptake. Our findings suggest that the effect of $\left[{ }^{18} \mathrm{~F}\right] \mathrm{FDG}$ uptake on RILT depended on the location of the 5\% to $20 \%$ highest uptake voxels with respect to the dose distribution. A large overlap between these voxels and the part of the volume that received 2 to 5 Gy or more increased the effect. Thus, not only is the amount of $\left[{ }^{18} \mathrm{~F}\right] \mathrm{FDG}$ uptake in the lungs of importance for RILT but also the dose to these regions and the anatomical location. If these high- $\left[{ }^{18} \mathrm{~F}\right]$ FDG-uptake regions could be shielded from the treatment fields, the risk of RILT might decrease.

Table 4. Coefficients of the final multivariable logistic regression model

\begin{tabular}{lclcc}
\hline \multicolumn{1}{c}{ Variable } & Coefficient & SE & Odds ratio (95\% CI) & $p$ value \\
\hline Constant & -7.9 & 2.7 & $3.610^{-4}\left(1.8910^{-6}\right.$ to 0.070$)$ \\
Age & 0.054 & 0.025 & $1.06(1.00-1.11)$ & $\mathbf{0 . 0 2 9}$ \\
SUV $_{95}$ & 1.5 & 0.67 & $4.28(1.16-15.8)$ & $\mathbf{0 . 0 1 6}$ \\
Dyspnea pre-RT & & & $0.20(0.069-0.60)$ & $\mathbf{0 . 0 0 4 4}$ \\
$\quad 1$ & -1.6 & 0.55 & $0.20(0.036-1.16)$ \\
\hline 2 & -1.6 & 0.88 & \\
\hline
\end{tabular}

Abbreviations: $\mathrm{SE}=$ standard error of the coefficients; $\mathrm{CI}=$ confidence interval; $\mathrm{SUV}_{95}=95$ th percentile of the SUV in the lungs. 
Table 5. Coefficients of the models with significant interaction terms

\begin{tabular}{|c|c|c|c|c|}
\hline Variable & Coefficient & SE & Odds ratio $(95 \% \mathrm{CI})$ & $p$ value* \\
\hline \multicolumn{5}{|l|}{$\mathrm{SUV}_{80}$ and $\mathrm{V}_{2}$} \\
\hline Constant & -0.048 & 2.4 & $0.95\left(8.110^{-3}\right.$ to112) & 0.036 \\
\hline $\mathrm{SUV}_{80}$ & -2.5 & 3.1 & $0.083\left(1.810^{-4}\right.$ to 37.5$)$ & \\
\hline Overlap $\mathrm{SUV80,2 \textrm {Gy }}$ & -0.33 & 0.041 & $0.73(0.66-0.78)$ & \\
\hline Interaction term & 0.071 & 0.052 & $1.07(0.97-1.19)$ & \\
\hline \multicolumn{5}{|l|}{$\mathrm{SUV}_{90}$ and $\mathrm{V}_{2}$} \\
\hline Constant & -0.14 & 2.1 & $0.87(0.014-53.3)$ & 0.011 \\
\hline $\mathrm{SUV}_{90}$ & -0.60 & 1.9 & $0.55(0.012-24.6)$ & \\
\hline Overlap ${ }_{S U V 90,2 G y}$ & -0.63 & 0.060 & $0.53(0.47-0.60)$ & \\
\hline Interaction term & 0.59 & 0.054 & $1.80(1.62-2.01)$ & \\
\hline \multicolumn{5}{|l|}{$\mathrm{SUV}_{95}$ and $\mathrm{V}_{2}$} \\
\hline Constant & 3.5 & 2.8 & $34\left(0.14-8.2510^{3}\right)$ & 0.015 \\
\hline $\mathrm{SUV}_{95}$ & -4.7 & 2.7 & $0.009\left(5.010^{-5}\right.$ to 1.71$)$ & \\
\hline Overlap $_{\text {SUV95, 2Gy }}$ & -0.087 & 0.045 & $0.92(0.84-1.00)$ & \\
\hline Interaction term & 0.091 & 0.041 & $1.10(1.01-1.19)$ & \\
\hline \multicolumn{5}{|l|}{$\mathrm{SUV}_{95}$ and $\mathrm{V}_{5}$} \\
\hline Constant & 2.4 & 2.7 & $11\left(0.055-2.0210^{3}\right)$ & 0.046 \\
\hline $\mathrm{SUV}_{95}$ & -3.3 & 2.5 & $0.036\left(2.610^{-4}\right.$ to 5.05$)$ & \\
\hline Overlap ${ }_{\text {SUV } 95,5 G y}$ & -0.086 & 0.050 & $0.92(0.83-1.01)$ & \\
\hline Interaction term & 0.087 & 0.046 & $1.09(1.00-1.19)$ & \\
\hline
\end{tabular}

Abbreviations: $\mathrm{SE}=$ standard error of the coefficients; $\mathrm{CI}=$ confidence interval; $\mathrm{V}_{2}$ and $\mathrm{V}_{5}=$ volume of the lungs receiving 2 and 5 Gy or more. SUV = standardized uptake values in the lung; numerical subscripts indicate percentiles; Overlap SUV95, $2 \mathrm{~Gy}_{\mathbf{3}}=$ relative volume of the voxels with $\mathrm{SUV}>\mathrm{SUV}_{95}$ that received more than $2 \mathrm{~Gy}$.

* $p$ value indicates the significance of the interaction term.

Previous studies have associated increased $\left[{ }^{18} \mathrm{~F}\right] \mathrm{FDG}$ uptake during or after therapy with RILT $(19,20,22-24)$, but this is the first study that correlates pretreatment $\left[{ }^{18} \mathrm{~F}\right] \mathrm{FDG}$ uptake in the lungs to RILT after therapy. The identification of patients at high risk for RILT on the basis of a pretreatment $\left[{ }^{18} \mathrm{~F}\right]$ FDG-PET-CT scan would have

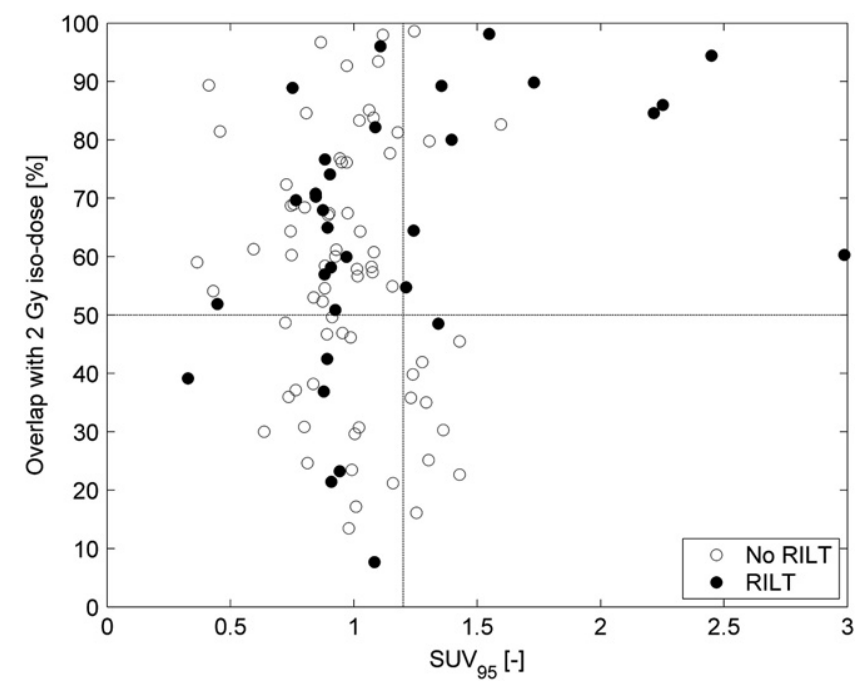

Fig. 2. The 95th percentile of the SUV in the lungs $\left(\mathrm{SUV}_{95}\right)$ before RT vs. the overlap between the voxels with $\mathrm{SUV}>\mathrm{SUV}_{95}$ and the volume receiving more than $2 \mathrm{~Gy}$. Patients with and without radiation-induced lung toxicity (RILT) are indicated by closed and open circles, respectively. Dashed lines divide the data into (arbitrary) quadrants based on $\mathrm{SUV}_{95}$ and the overlap. Patients with both a high $\mathrm{SUV}_{95}$ and a high overlap were most likely to have RILT. obvious advantages for tailoring treatment strategies to the individual patient.

The volume of the lung receiving a low dose has been related to RILT previously (7), and the current study suggests that these low-dose volumes could be even more important if the overlap with high- $\left[{ }^{18} \mathrm{~F}\right] \mathrm{FDG}$-uptake regions is large. Intensity-modulated RT and intensity-modulated arc therapies generate dose distributions with larger low-dose regions than conformal RT and might therefore not be beneficial for patients with a high pretreatment level of $\left[{ }^{18} \mathrm{~F}\right]$ FDG uptake.

A previous study has shown that irradiation of the inferior parts of the lung increases the risk of RILT (5), suggesting that the lower parts of the lung are more prone to complications than the other parts. This is in line with the current study, in which patients with RILT were more likely to have the high $\left[{ }^{18} \mathrm{~F}\right] \mathrm{FDG}$ uptake in the lower parts of the lungs than in other lung regions. In the peripheral parts of lung, the density of functional bronchi is larger than in other parts of the lungs, Especially in rest, these regions are responsible for sufficient ventilation and gas exchange.

With univariable logistic regression, an increased lung density was significantly related to RILT, but the statistical significance was lost in the multivariable model. This indicates that a $\left[{ }^{18} \mathrm{~F}\right]$ FDG-PET-CT scan has added value for the prediction of RILT compared to a CT scan alone.

Besides $\left[{ }^{18} \mathrm{~F}\right] \mathrm{FDG}$ uptake, the final multivariable model contained age and the dyspnea score before RT. The importance of high age has been demonstrated previously $(8,9)$. The dyspnea score before RT was negatively correlated with an increase in dyspnea. 


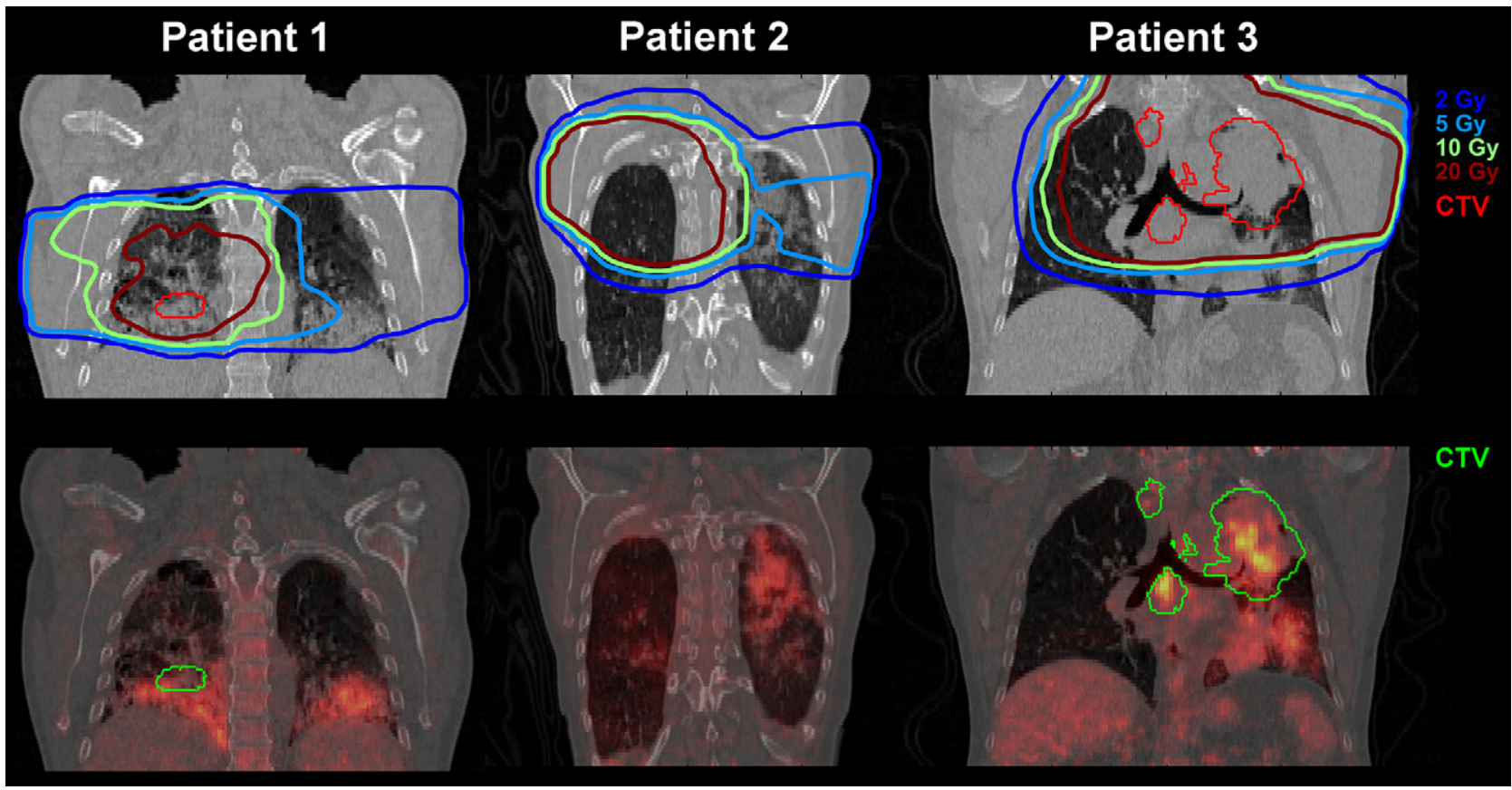

Fig. 3. Three examples of patients with high $\left[{ }^{18} \mathrm{~F}\right] \mathrm{FDG}$ uptake in the lungs before the start of RT who had RILT during or after treatment. The CT and iso-dose lines are shown in the top row and the PET-CT in the second row are shown. The CTVs are also indicated.

A number of other parameters that were previously found to be predictors of RILT, such as chemotherapy, $\mathrm{V}_{20}$, and MLD $(1,5,6)$ were tested, but none was significant in the current dataset. This can be explained partly by the maximum MLD in this study, which was too low to find a strong dose effect relationship, because between 0 and 20 Gy, the incidence of RILT increases only moderately $(1,9)$. Another explanation is that we used a different endpoint. Most studies ignored the fact that RILT-like symptoms, such as dyspnea, could have been present before RT and could be mistaken for RILT after RT, even if the symptoms were not aggravated. In the present dataset, a substantial number of patients with severe dyspnea (grade, $\geq 2$ ) after RT already had severe dyspnea before RT. For these patients, the dyspnea clearly was not induced by radiation. Therefore, ignoring the baseline scores leads to a large bias for the endpoint $(11,28)$. In general, choosing a good endpoint for RILT is challenging (29). Dyspnea is clinically relevant, but the measurement is subjective, and dyspnea can also be caused by tumor progression. The alternative, radiation pneumonitis, can be scored more objectively by using chest X-ray or CT. However, the important drawback is that patients with abnormalities on imaging often do not have any complaints. In our opinion, an increase in dyspnea score compared to the pre-RT score is the most transparent endpoint for radiation-induced lung toxicity.

Eighteen percent of the patients included in this study had a decrease in dyspnea score after RT compared to the baseline score. We ignored these decreases and pooled the patients together with those that remained stable. A thorough analysis of these patients is the subject of future research.
This study has a few limitations that need to be addressed. First, the number of patients with RILT was too small to test the interaction effect of the overlap between $\left[{ }^{18} \mathrm{~F}\right] \mathrm{FDG}$ and dose volumes in combination with the non- $\left[{ }^{18} \mathrm{~F}\right]$ FDG-based variables. Second, due to the partial volume effect and breathing motion, the $\left[{ }^{18} \mathrm{~F}\right] \mathrm{FDG}$ uptake signal was smeared out. This means that volumes of high $\left[{ }^{18} \mathrm{~F}\right] \mathrm{FDG}$ uptake might have been smaller than reported here and that the $\mathrm{SUV}_{90}$ and $\mathrm{SUV}_{95}$ were underestimated. In the future, the effect of the breathing motion can be reduced using 4D PET-CT imaging. Third, the number of statistical tests performed in this study was large, which makes random significant results (type I errors) likely. Because of the explorative character of the analysis, we chose not to correct for this. Fourth, this was a monoinstitutional explorative study, and the results need to be validated in a larger independent dataset, preferably from a different institute. The results nevertheless strongly support the need for a prospective study of the combined effect of $\left[{ }^{18} \mathrm{~F}\right] \mathrm{FDG}$ uptake and dose on RILT.

\section{CONCLUSIONS}

In this study, we have demonstrated that the risk of RILT increased $(\mathrm{OR}=4.3)$ with the 95th percentile of the $\left[{ }^{18} \mathrm{~F}\right] \mathrm{FDG}$ uptake in the lungs (excluding CTV) prior to (chemo) radiation. The effect became more pronounced as the fraction of the $5 \%, 10 \%$, and $20 \%$ highest SUV voxels that received more than 2 to $5 \mathrm{~Gy}$ increased. Our findings may enable both the selection of patients at high risk for radiation-induced lung damage and strategies to decrease the risk by using more sophisticated RT techniques to avoid areas in the lung with high $\left[{ }^{18} \mathrm{~F}\right] \mathrm{FDG}$ uptake. 


\section{REFERENCES}

1. Kwa SL, Lebesque JV, Theuws JC, et al. Radiation pneumonitis as a function of mean lung dose: an analysis of pooled data of 540 patients. Int J Radiat Oncol Biol Phys 1998;42:1-9.

2. Graham MV, Purdy JA, Emami B, et al. Clinical dose-volume histogram analysis for pneumonitis after 3D treatment for non-small-cell lung cancer (NSCLC). Int J Radiat Oncol Biol Phys 1999;45:323-329.

3. Hope AJ, Lindsay PE, El Naqa I, et al. Modeling radiation pneumonitis risk with clinical, dosimetric, and spatial parameters. Int J Radiat Oncol Biol Phys 2006;65:112-124.

4. Chen S, Zhou S, Yin FF, et al. Investigation of the support vector machine algorithm to predict lung radiation-induced pneumonitis. Med Phys 2007;34:3808-3814.

5. Bradley JD, Hope A, El Naqa I, et al. A nomogram to predict radiation pneumonitis, derived from a combined analysis of RTOG 9311 and institutional data. Int J Radiat Oncol Biol Phys 2007;69:985-992.

6. Das SK, Chen S, Deasy JO, et al. Combining multiple models to generate consensus: Application to radiation-induced pneumonitis prediction. Med Phys 2008;35:5098-5109.

7. Yom SS, Liao Z, Liu HH, et al. Initial evaluation of treatmentrelated pneumonitis in advanced-stage non-small-cell lung cancer patients treated with concurrent chemotherapy and intensity-modulated radiotherapy. Int J Radiat Oncol Biol Phys 2007;68:94-102.

8. Claude L, Perol D, Ginestet C, et al. A prospective study on radiation pneumonitis following conformal radiation therapy in non-small-cell lung cancer: Clinical and dosimetric factors analysis. Radiother Oncol 2004;71:175-181.

9. Dehing-Oberije C, De Ruysscher D, van Baardwijk A, et al. The importance of patient characteristics for the prediction of radiation-induced lung toxicity. Radiother Oncol 2009;91: 421-426.

10. Tucker SL, Liu HH, Liao Z, et al. Analysis of radiation pneumonitis risk using a generalized Lyman model. Int J Radiat Oncol Biol Phys 2008;72:568-574.

11. van Baardwijk A, Wanders S, Boersma L, et al. Mature results of an individualized radiation dose prescription study based on normal tissue constraints in stage I-III non-small-cell lung cancer. J Clin Oncol 2010;28:1380-1386.

12. Tsoutsou PG, Koukourakis MI. Radiation pneumonitis and fibrosis: Mechanisms underlying its pathogenesis and implications for future research. Int J Radiat Oncol Biol Phys 2006; 66:1281-1293.

13. Behzadi A, Ung Y, Lowe V, et al. The role of positron emission tomography in the management of non-small-cell lung cancer. Can J Surg 2009;52:235-242.

14. Stumpe KD, Dazzi H, Schaffner A, et al. Infection imaging using whole-body FDG-PET. Eur J Nucl Med 2000;27:822-832.

15. Rennen HJ, Boerman OC, Oyen WJ, et al. Imaging infection/inflammation in the new millennium. Eur J Nucl Med 2001;28: 241-252.
16. Basu S, Chryssikos T, Moghadam-Kia S, et al. Positron emission tomography as a diagnostic tool in infection: present role and future possibilities. Semin Nucl Med 2009;39: 36-51.

17. Zhuang H, Yu JQ, Alavi A. Applications of fluorodeoxyglucosePET imaging in the detection of infection and inflammation and other benign disorders. Radiol Clin North Am 2005;43:121-134.

18. Alavi A, Gupta N, Alberini JL, et al. Positron emission tomography imaging in nonmalignant thoracic disorders. Semin Nucl Med 2002;32:293-321.

19. Lin P, Delaney G, Chu J, et al. Fluorine-18 FDG dual-head gamma camera coincidence imaging of radiation pneumonitis. Clin Nucl Med 2000;25:866-869.

20. Hassaballa HA, Cohen ES, Khan AJ, et al. Positron emission tomography demonstrates radiation-induced changes to nonirradiated lungs in lung cancer patients treated with radiation and chemotherapy. Chest 2005;128:1448-1452.

21. Guerrero T, Johnson V, Hart J, et al. Radiation pneumonitis: Local dose versus [18F]-fluorodeoxyglucose uptake response in irradiated lung. Int J Radiat Oncol Biol Phys 2007;68: 1030-1035.

22. Song H, Yu JM, Kong FM, et al. [18F]2-fluoro-2-deoxyglucose positron emission tomography/computed tomography in predicting radiation pneumonitis. Chin Med J (Engl) 2009;122: 1311-1315.

23. Hart JP, McCurdy MR, Ezhil M, et al. Radiation pneumonitis: Correlation of toxicity with pulmonary metabolic radiation response. Int J Radiat Oncol Biol Phys 2008;71: 967-971.

24. De Ruysscher D, Houben A, Aerts HJ, et al. Increased (18)F-deoxyglucose uptake in the lung during the first weeks of radiotherapy is correlated with subsequent Radiation-Induced Lung Toxicity (RILT): A prospective pilot study. Radiother Oncol 2009;91:415-420.

25. van Baardwijk A, Bosmans G, Bentzen SM, et al. Radiation dose prescription for non-small-cell lung cancer according to normal tissue dose constraints: An in silico clinical trial. Int $J$ Radiat Oncol Biol Phys 2008;71:1103-1110.

26. van Baardwijk A, Bosmans G, Boersma L, et al. Individualized radical radiotherapy of non-small-cell lung cancer based on normal tissue dose constraints: A feasibility study. Int J Radiat Oncol Biol Phys 2008;71:1394-1401.

27. Rabe KF, Hurd S, Anzueto A, et al. Global strategy for the diagnosis, management, and prevention of chronic obstructive pulmonary disease: GOLD executive summary. Am J Respir Crit Care Med 2007; 176:532-555.

28. De Ruysscher D, Dehing C, Yu S, et al. Dyspnea evolution after high-dose radiotherapy in patients with non-small-cell lung cancer. Radiother Oncol 2009;91:353-359.

29. Faria SL, Aslani M, Tafazoli FS, et al. The challenge of scoring radiation-induced lung toxicity. Clin Oncol ( $R$ Coll Radiol) 2009;21:371-375. 